\title{
Neutrophil-Derived Reactive 0xygen Orchestrates Epithelial Cell Signaling Events during Intestinal Repair
}

\author{
Jason D. Matthews, ${ }^{*}$ Joshua A. Owens, ${ }^{\dagger}$ Crystal R. Naudin, ${ }^{\dagger}$ Bejan J. Saeedi, ${ }^{*}$ Ashfaqul Alam, ${ }^{*}$ April R. Reedy, ${ }^{*}$
} Benjamin H. Hinrichs, ${ }^{*}$ Ronen Sumagin, ${ }^{\star}$ Andrew S. Neish, ${ }^{*}$ and Rheinallt M. Jones

From the Department of Pathology* and the Division of Gastroenterology, Hepatology, and Nutrition, ${ }^{\dagger}$ Department of Pediatrics, Emory University School of Medicine, Atlanta, Georgia; and the Department of Pathology, ${ }^{\ddagger}$ Northwestern University Feinberg School of Medicine, Chicago Illinois

\author{
Accepted for publication \\ July 30, 2019. \\ Address correspondence to \\ Rheinallt M. Jones, Ph.D., \\ Division of Gastroenterology, \\ Hepatology, and Nutrition, \\ Department of Pediatrics, \\ Emory University School of \\ Medicine, 615 Michael St, \\ Atlanta, GA 30322. E-mail: \\ rjones5@emory.edu.
}

\begin{abstract}
Recent evidence has demonstrated that reactive oxygen (eg, hydrogen peroxide) can activate host cell signaling pathways that function in repair. We show that mice deficient in their capacity to generate reactive oxygen by the NADPH oxidase 2 holoenzyme, an enzyme complex highly expressed in neutrophils and macrophages, have disrupted capacity to orchestrate signaling events that function in mucosal repair. Similar observations were made for mice after neutrophil depletion, pinpointing this cell type as the source of the reactive oxygen driving oxidation-reduction protein signaling in the epithelium. To simulate epithelial exposure to high levels of reactive oxygen produced by neutrophils and gain new insight into this oxidation-reduction signaling, epithelial cells were treated with hydrogen peroxide, biochemical experiments were conducted, and a proteome-wide screen was performed using isotope-coded affinity tags to detect proteins oxidized after exposure. This analysis implicated signaling pathways regulating focal adhesions, cell junctions, and maintenance of the cytoskeleton. These pathways are also known to act via coordinated phosphorylation events within proteins that constitute the focal adhesion complex, including focal adhesion kinase and Crk-associated substrate. We identified the Rho family small GTP-binding protein Ras-related C3 botulinum toxin substrate 1 and p21 activated kinases 2 as operational in these signaling and localization pathways. These data support the hypothesis that reactive oxygen species from neutrophils can orchestrate epithelial cell-signaling events functioning in intestinal repair. (Am J Pathol 2019, 189: 2221-2232; https://doi.org/10.1016/j.ajpath.2019.07.017)
\end{abstract}

Injury to the intestinal epithelium can occur because of multiple clinical conditions that include infectious or idiopathic inflammatory diseases, ischemia, or irradiation. Generally, the epithelium has a remarkable capacity to repair itself, thereby preventing fluid/electrolyte imbalance and systemic exposure to luminal antigens or pathogens. However, many clinical conditions, such as inflammatory bowel disease (ulcerative colitis or Crohn disease), lead to intestinal injury that does not heal. Therefore, the molecular mechanisms and functional elements that mediate epithelial barrier wound repair are of intense investigative interest.

The intestinal epithelium is a dynamic barrier separating the luminal stream from the underlying subepithelial compartments. This barrier is actively renewed by proliferation of progenitor stem cells within crypts, migration of epithelial cells along the crypt-villous axis, and programmed shedding at the luminal surface. This process occurs in 5 to 7 days in humans, while concomitantly maintaining barrier function. ${ }^{1,2}$ Many cell-signaling pathways have been shown to function in wound repair, including networks that are activated in response to the controlled generation of reactive oxygen within cells. ${ }^{3-6}$ The controlled and deliberate generation of reactive oxygen can occur as a result of the catalytic activity harbored within cells,

Supported by Crohn's and Colitis Foundation of America grant CDA\#451678 (J.D.M.), National Institute of Diabetes and Digestive and Kidney Diseases training grant T32DK007771-06 (A.R.R.), NIH research training grant F30DK117570 (B.J.S.), and American Heart Association fellowship 19POST34370006 (C.R.N.); and in part by NIH grants R01DK098391 (R.M.J.) and R01DK071604 and R01AI064462 (A.S.N.).

Disclosures: None declared. 
either intrinsically at low levels or at elevated levels in response to sensing exogenous stimuli. For example, sensing of molecular elements specific to bacteria and subsequent generation of reactive oxygen by neutrophils are a long-established host microbicidal response to bacteria, termed the respiratory burst. ${ }^{7}$ This process is catalyzed by a specific NADPH oxidase 2 (Nox2), of which gp91phox is a membrane-bound component found primarily in macrophages and neutrophils and required for their bactericidal action. ${ }^{8}$ Circulating immune cells recruited to the site of a wound exert indiscriminate microbicidal activity by the generation of reactive oxygen. ${ }^{9}$ In addition to microbicidal activity, deliberate generation of reactive oxygen within epithelial cells via the NADPH oxidase Nox1 has an established role in modulating cell signaling, including regulatory events that initiate and promote restitution and healing of a damaged epithelium. ${ }^{3,10,11}$ Reactive oxygen-mediated signaling occurs through the rapid and reversible oxidation of cysteine residues within specific target proteins, usually regulatory enzymes, thus allowing for graded perception of intracellular reactive oxygen concentrations and control of critical steps in signal transduction pathways. ${ }^{12,13}$ The specificity of biological responses to the altered levels of reactive oxygen is dependent on the specific reactive oxygen species molecule type generated, the intensity of the signal, the subcellular sites of production, or the developmental stage of the cell. ${ }^{14,15}$

Our research group recently reported that oxidationreduction (redox) signaling could influence the phosphorylation of Crk-associated substrate (Cas) via a mechanism that requires the activity of the Abelson murine leukemia viral oncogene homolog 1 (ABL1) kinase. ${ }^{16}$ Specifically, Cas, which acts as a mechanosensor in focal adhesions and is essential for cell movement is phosphorylated at residue Y410 in response to elevated levels of exposure to hydrogen peroxide. In addition, within a restituting, mechanically inflicted wound, phosphorylated CAS delocalizes from focal adhesions to cell junctions, which is a phenotype observed in actively restituting intestine tissue. ${ }^{16}$ Interestingly, focal adhesion kinase (FAK) has also been shown to localize to cell junctions and control permeability in both the endothelium ${ }^{17-22}$ and epithelium. ${ }^{23,24}$ These findings point to the possibility of cross talk between focal adhesion proteins and cell junction proteins. ${ }^{25}$ As stated above, immune cells also secrete high levels of extracellular reactive oxygen into the tissue wound environment. ${ }^{26}$ This event has long been assumed to represent deleterious collateral damage necessary for killing of phagocytosed bacteria. However, this reactive oxygen can form a concentration gradient with signaling function. Therefore, at a certain distance, the gradient of immune cell-generated reactive oxygen is inevitably sensed by cells within the adjacent epithelium and possibly results in the physiological reversible oxidation of cysteine residues within specific target proteins. To date, the extent to which immune cell-derived reactive oxygen orchestrates cell-signaling events during intestinal epithelium wound repair has not been fully described.
The aim of this study was to investigate the cell signaling pathways regulated by reactive oxygen that function to induce wound restitution. A variety of genetic, imaging, biochemical, and proteomic techniques were used, which showed that neutrophil-derived reactive oxygen produced at the site of intestinal injury function in activating signaling events in the epithelium that regulate cytoskeleton dynamics, focal adhesion, and cell junction activity.

\section{Materials and Methods}

\section{Mice}

Wild-type C57BL/6 (stock number 000664) and gp91phox-null (stock number 002365) mice were purchased from The Jackson Laboratory (Bar Harbor, ME) and housed in the Emory University (Atlanta, GA) Whitehead Animal facility for 2 weeks before experimentation. To account for host-microbiome reciprocal interactions, the microbiome of each group of mice was normalized by routinely exchanging bedding between cages for 2 weeks before experimentation.

\section{Wound Biopsies by Mechanical Injury in the Colon}

Biopsy wounding was performed, as previously described. ${ }^{16}$ Briefly, to generate discrete mucosal injuries in the mouse colon and to monitor their regeneration, a high-resolution miniaturized colonoscope system (Coloview Veterinary Endoscope; Karl Storz, Goleta, CA) was used. This system consisted of a miniature rigid endoscope (1.9-mm outer diameter), a xenon light source, a triple-chip, high-resolution charge-coupled device camera, and an operating sheath with $3 \mathrm{~F}$ instrument channel and air/water injection bulb to regulate inflation of the mouse colon (all from Karl Storz). Endoscopic procedures were viewed with high-resolution $(1024 \times 768$ pixel) images on a flat-panel color monitor. The night before the initial biopsy injury, food was removed from the mouse cages. The following morning, mice were anesthetized by using ketamine and xylazine, and the endoscope with outer operating sheath was inserted to the mid-descending colon and the mucosa was surveyed to the anorectal junction. Then, a flexible biopsy forceps with a diameter of $3 \mathrm{~F}$ was used to remove single full-thickness areas of the entire mucosa and submucosa. Particular attention was taken to avoid penetration of the muscularis propria. Each mouse received biopsy injuries at three to five sites along the dorsal side of the colon (spacing was $>5 \mathrm{~mm}$ ). After the defined experimental period, colons were dissected and tissue was embedded for histopathologic and immunofluorescence analysis.

\section{DSS-Induced Mouse Model of Colon Injury and Neutrophil Depletion}

C57BL/6 and gp91phox-null mice were given drinking water with dextran sodium sulfate (DSS) at 3\%. This 
procedure causes erosions of the intestinal epithelium and consequently results in acute inflammation within 5 days. At 5 days, DSS is then discontinued and healing is monitored by assessing the disease activity index up until that extended to day 14 after initial addition of DSS in the water. The disease activity index is measured and calculated on the basis of stool consistency, weight loss, and presence or absence of detectable fecal blood. Colonic inflammation and damage were assessed by histologic scoring of immune cell infiltration, ulcerations, adhesions, and bowel wall thickness. Polymorphonuclear neutrophil depletion was achieved by two administrations of an anti-Ly6G antibody (100 $\mu \mathrm{g}$, intraperitoneally; Thermo Fisher Scientific, Waltham, MA): once, 12 hours before wounding; and second, 24 hours (day 1) after infliction of colonic wounds. The control group received a similar dose of the relevant IgG antibody. Polymorphonuclear neutrophil depletion $(>90 \%)$ was confirmed by flow cytometry.

\section{Cells, Transfection, Antibodies, and Reagents}

To measure transepithelial resistance, SK-CO-15 (a gift from Charles Parkos, University of Michigan, Ann Arbor, MI) cultured human epithelial cells were plated onto Corning transwells (24-well format; catalog number 3470; Corning Life Sciences, Tewksbury, MA) and monitored with an epithelial voltohmmeter. Transwells generate a cell culture that more closely mimics an in vivo environment, where chemical inhibitors or stimulants can be added to either the upper compartment (apical) or the lower compartment (basolateral) of the transwell. SK-CO-15 cells were also used for plasmid transfection assays and biochemical experiments to analyze protein signaling or protein-protein interactions. Transfections were performed in a 24-well plate, with each well receiving $0.5 \mu \mathrm{g}$ plasmid DNA/0.75 $\mu \mathrm{L}$ of Lipofectamine 2000 overnight treatment in Optimem cell culture media (both from Thermo Fisher Scientific). Unless otherwise noted, transfected or chemically treated cells were harvested and analyzed after 24 hours of incubation. FAK inhibitor PF-562271 was used at $500 \mathrm{nmol} / \mathrm{L}$ final concentration, and the p21-activated kinase 2 (PAK2) inhibitor FRAX597 (Selleckchem, Houston, $\mathrm{TX}$ ) was used at $2.5 \mu \mathrm{mol} / \mathrm{L}$ final concentration.

\section{Immunofluorescence, Proximity Ligation, and Microscopy}

Cells were fixed in $4 \%$ formaldehyde, ice cold, for $10 \mathrm{mi}-$ nutes and then permeabilized with $0.5 \%$ Triton X-100 for 7 minutes. For mouse sections, tissues were fixed in ice-cold formaldehyde for 15 minutes and permeabilized in Triton X-100 for 15 minutes. Samples were blocked in phosphatebuffered saline/bovine serum albumin and then probed consecutively with primary and fluorescent conjugate secondary antibodies (goat anti-mouse, anti-rabbit, or anti-rat) with appropriate species reactivity (Molecular Probes,
Eugene, OR). For proximity ligation, the samples were processed according to the Duolink proximity ligation assay technology (Sigma-Aldrich, St. Louis, MO) instructions, with slight modifications. Briefly, after incubation with primary antibody, samples were exposed to the Duolink secondary antibodies containing conjugated nucleic acid probes for 45 minutes, and then ligated for 30 minutes at $37^{\circ} \mathrm{C}$, after which DNA polymerase was added with a master mix of fluorescent nucleotides and allowed to react for 1 hour. Images were obtained on an Olympus F1000 confocal microscope (Olympus America Inc., Center Valley, PA).

\section{BIAM Pull-Down Assay}

The biotin-iodoacetamide (BIAM) pull-down assay was performed, as described previously, ${ }^{27}$ without modification. Briefly, epithelial cell monolayers were lysed, the insoluble material was removed by centrifugation, and the lysates were adjusted to $25 \mu \mathrm{mol} / \mathrm{L}$ (biotinylated iodoacetamide) BIAM and incubated on ice in the dark for 45 minutes. After removal of unbound biotin label with a desalting column, biotinylated proteins were immobilized onto streptavidin agarose for 1 hour. After extensive washing and heat denaturing, SDSPAGE and Western blot analysis were performed.

\section{Isotope-Coded Affinity Tags}

The Cleavable ICAT Reagent for Protein Labeling (stock keeping unit number 4339036) was obtained from SCIEX (Framingham, MA). Isotope-coded affinity tag (ICAT) and tandem mass spectrometry analysis was performed essentially, as previously described, ${ }^{27}$ with minor modification. Briefly, trichloroacetic acid precipitated proteins from cell lysates were incubated with a heavy ICAT reagent to label reduced cysteines, followed by a second trichloroacetic acid precipitation, disulfide reduction with tris(2-carboxyethyl) phosphine (TCEP), and then labeling of newly reduced cysteines with a light ICAT reagent. After overnight trypsin digestion and an on-column purification (first-round anion exchange, second-round streptavidin) of biotinylated peptides with heavy and light labels, samples were vacuum dried before processing. Peptides were resuspended in trifluoroacetic acid/acetonitrile and loaded onto a C18-fused silica column before elution and injection into a mass spectrometer, where they were then scanned, resolved, and trapped before being dynamically excluded; and the raw values were used to search a human database for corresponding peptide matches, with a false discovery rate set to $1 \%$.

\section{Immunoprecipitation and Western Blot Analysis}

Protein lysates (approximately $1 \mathrm{mg}$ protein) were mixed with preloaded protein-G agarose beads (Sigma-Aldrich) containing the appropriate immunoprecipitating antibody and incubated with end-over-end mixing for 2 hours at $4^{\circ} \mathrm{C}$. Beads with immune complexes were isolated by 
centrifugation and washed several times with lysis buffer (1\% Triton X-100/tris-buffered saline) before being heat denatured and analyzed by Western blot analysis. To this end, blotting was performed using standard SDS-PAGE and transfer conditions (100 V for gel, $350 \mathrm{~mA}$ for transfer). Blots were blocked in milk or, in the case for phosphoblotting, 5\% bovine serum albumin was used. Primary antibodies were incubated with blots overnight at $4{ }^{\circ} \mathrm{C}$, and the secondary electrochemiluminescence conjugate (donkey anti-mouse or donkey anti-rabbit; Jackson Immunoresearch Inc., West Grove, PA) was incubated for 2 hours after multiple washes with tris-buffered saline/Tween-20. The electrochemiluminescence signal was captured by a digital camera system (KwikQuant; Kindle Biosciences, Greenwich, CT) and adjusted for brightness and contrast. Experiments were repeated multiple times to ensure accuracy.

\section{Results}

Reactive 0xygen Produced by Nox2/gp91phox Influences Disease Activity and Cas Phosphorylation in an Injured Intestinal Mucosa

Other investigations have reported on the negative effects of the loss of neutrophil activity on recovery using the 2,4,6trinitrobenzene sulfonic acid-colitis model that includes the development of a transmural inflammation that resembles the histopathologic lesions that develop in human Crohn disease. ${ }^{28}$ The effect of the loss of reactive oxygen generated by infiltrating immune cells was assessed on disease intensity and recovery rates using a DSS model of colitis and gut injury. Mice that are null for Nox 2 activity by genetic ablation of gp91phox exhibited significantly increased disease activity index during DSS treatment and recovered at a significantly slower rate after the removal of DSS from the drinking water, compared with wild-type controls (Figure $1 \mathrm{~A}-\mathrm{C}$ ). These data point to the contributing influence of immune cell-generated reactive oxygen in disease intensity and, in particular, in the restitution of injured gut tissue.

Within biopsy wounds inflicted on the colonic mucosa, the localization of phosphorylated Cas (p-Cas) deviates from being restricted to focal adhesions at the base of columnar enterocytes in uninjured tissue, to also emerge on the lateral edges of enterocytes in wounded tissue. The emergence of $\mathrm{p}$-Cas on the lateral edges of enterocytes also occurs after the addition of hydrogen peroxide to polarized colonic epithelial monolayers. ${ }^{16}$ Because hydrogen peroxide alone could recapitulate the phenotype of the emergence of $\mathrm{p}$-Cas on the lateral edges of enterocytes, and because high levels of hydrogen peroxide are generated by immune cells recruited to the site of the wound, we hypothesized that immune cell-generated hydrogen peroxide potentiates the emergence of $\mathrm{p}$-Cas on the lateral edges of enterocytes within wounds. To test this hypothesis, biopsy wounds were inflicted in the colons of mice that lack Nox 2 activity (null for gp91phox, the primary driver of superoxide generation), with Nox 2 being the holoenzyme that is essential for catalyzing the generation of reactive oxygen in immune cells. Although the emergence of p-Cas occurred on the lateral edges of enterocytes of wild-type C57BL/6 control mice at 48 hours after wound infliction, no p-Cas was detected on the lateral edges of enterocytes within wounds lacking Nox2 activity (Figure 1D), demonstrating the requirement of immune cell-generated reactive oxygen for this phenotype. In addition, depletion of circulating neutrophils from mice by i.p. administration of anti-Ly6G elicited the same results as observed in Nox2-null mice, in which no p-Cas was detected within wounds after neutrophil depletion. These data indicate that a major source of exogenous reactive oxygen within wounds emanates from recruited neutrophils at the site of intestinal injury (Figure 1D).

\section{Identification of Hydrogen Peroxide-Responsive Signaling Pathways in Cultured Epithelial Cells}

Next, the epithelial signaling pathways affected by exposure to high levels of exogenous reactive oxygen species were studied. A proteome-wide screen was performed to detect proteins oxidized after exposure to $1 \mathrm{mmol} / \mathrm{L} \mathrm{H}_{2} \mathrm{O}_{2}$ using the ICAT method. ${ }^{29}$ This concentration of hydrogen peroxide was selected because it was the lowest concentration found to elicit detectable phosphorylation of Cas in vitro. ${ }^{16}$ The ICAT approach involves a two-step labeling of reduced and reversibly oxidized cysteine residues within proteins using iodoacetamide. First, reduced cysteines are labeled with a heavy isotope. Then, in a second reaction, oxidized cysteines are reduced with TCEP and reacted with a light isotope. Therefore, by contrasting the ratio of cysteine residues labeled in untreated cells to ratios of cysteine residues labeled in cells exposed to hydrogen peroxide, it is possible to identify residues that are sensitive to oxidation by exposure to reactive oxygen (Figure 2A). Cultured SK-CO-1 cells were exposed to $1 \mathrm{mmol} / \mathrm{L} \mathrm{H}_{2} \mathrm{O}_{2}$ for 15 minutes, whereupon cells were harvested and analyzed by ICAT. Approximately 2000 peptides corresponding to 115 different proteins that are significantly oxidized on hydrogen peroxide exposure were identified (Supplemental Table S1). The ICAT protocol relies on column purification of biotinylated peptides and, therefore, the whole proteome is not fully captured; thus, the data set only represents a fraction of the possible oxidized proteome. Graphical representation of the percentage oxidation for each of the captured peptides shows an overall shift from left to right, indicating that a large portion of the assayed proteome was oxidized when exposed to exogenous hydrogen peroxide (Figure 2B). Using the Search Tool for the Retrieval of Interacting Genes/Proteins ${ }^{30}$ analysis of those peptides with significant difference of $P<0.05$ or less revealed a diverse range of cellular functions for hydrogen peroxide-sensitive proteins (Table 1). Of particular interest was the identification of proteins with functions involving the formation of focal adhesions, tight junctions, and 
A

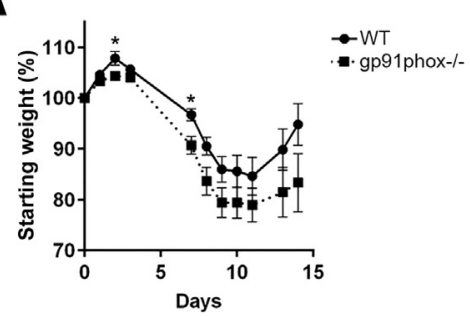

D

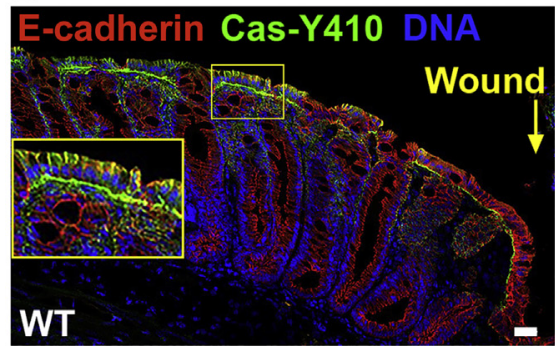

B

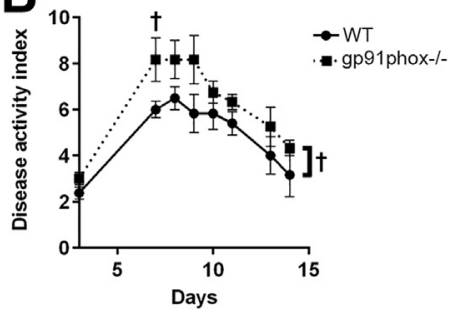

C

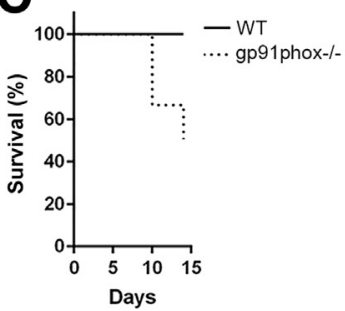

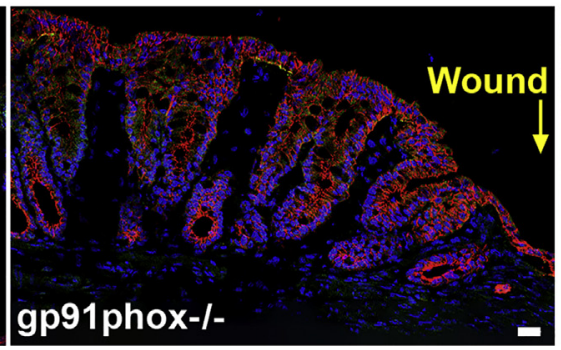

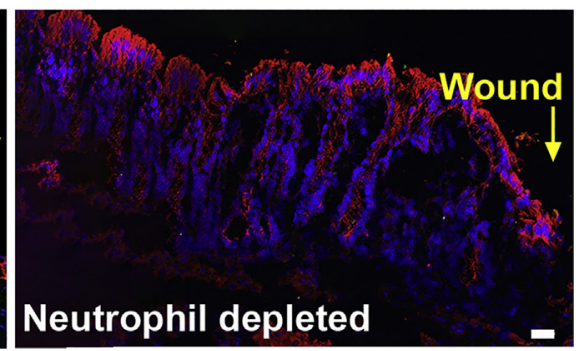

Figure 1 Immune cell-generated reactive oxygen influences disease activity and Crk-associated substrate (Cas) phosphorylation in an injured intestinal mucosa. A: Total body weight as a percentage of starting weight of wild-type (WT) and gp91phox-null mice during the treatment of $3 \%$ dextran sulfate sodium (DSS)-induced colitis. B: Disease activity index of mice described in $\mathbf{A}$ during the treatment of $3 \%$ DSS-induced colitis. $\mathbf{A}$ and $\mathbf{B}$ : The area under the curve was calculated for each mouse, and a $P$ value comparing the groups was obtained by a two-tailed $t$-test: $P=0.085(\mathbf{A})$ and $P=0.026$ (B). A and B: Asterisks (A) and daggers (B) represent time points at which groups were different. C: Survival of mice described in $\mathbf{A}$ during the treatment of $3 \%$ DSS-induced colitis. The Mantel-Cox log-rank test was used to compare the two curves $(P=0.057)$. D: Immunofluorescence analysis of phosphorylated Cas (green) and $\mathrm{E}$-cadherin (red) after injury to the intestinal mucosa by biopsy wounding in wild-type C57BL/6, gp91phox ${ }^{-1}$-null, and neutrophil-depleted mice. DNA is stained with DAPI (blue). Inset in first panel of $\mathbf{D}$ shows an enlarged view of the smaller boxed area, magnifying the image at the epithelial cell layer. Note strong expression of Cas-Y410 at the basolateral end of wild-type epithelial cells adjacent to the biopsy wound. This expression was absent in biopsy wounds inflicted on gp91 hhox $^{-/-}$- or neutrophil-depleted mice. $n=8(\mathbf{A}-\mathbf{C}) .{ }^{*} P<0.05$ (analysis of variance); ${ }^{\dagger} P<0.05$ (two-tailed $t$-test). Scale bars $=100 \mu \mathrm{m}(\mathbf{D})$.

construction and maintenance of the cytoskeleton (Supplemental Figure S1). These proteins also function in wound healing and tissue restitution in the gut, altogether implicating neutrophil-derived reactive oxygen as playing an important signaling role in adjacent epithelial cells to regulate cell migration in a restituting wound.

\section{Hydrogen Peroxide 0xidizes Cas, FAK, and Rac1}

To validate the findings of the ICAT analysis in Figure 2 that elements involved in the formation of focal adhesions within cells are sensitive to reactive oxygen, SK-CO-1 cells were subjected to $1 \mathrm{mmol} / \mathrm{L} \mathrm{H}_{2} \mathrm{O}_{2}$ for 15 minutes. Cells were harvested and oxidized proteins were identified using a BIAM cysteine labeling pull-down assay, ${ }^{27}$ where BIAM reacts with reduced thiols. If the thiol is oxidized after the addition of hydrogen peroxide, then BIAM will not react with the thiol on that protein and, therefore, the protein will not be pulled down by streptavidin agarose. Therefore, a diminished amount of protein in the pull-down fraction indicates that the protein harbors cysteine residues that have been oxidized by $1 \mathrm{mmol} / \mathrm{L} \mathrm{H}_{2} \mathrm{O}_{2}$. The results revealed
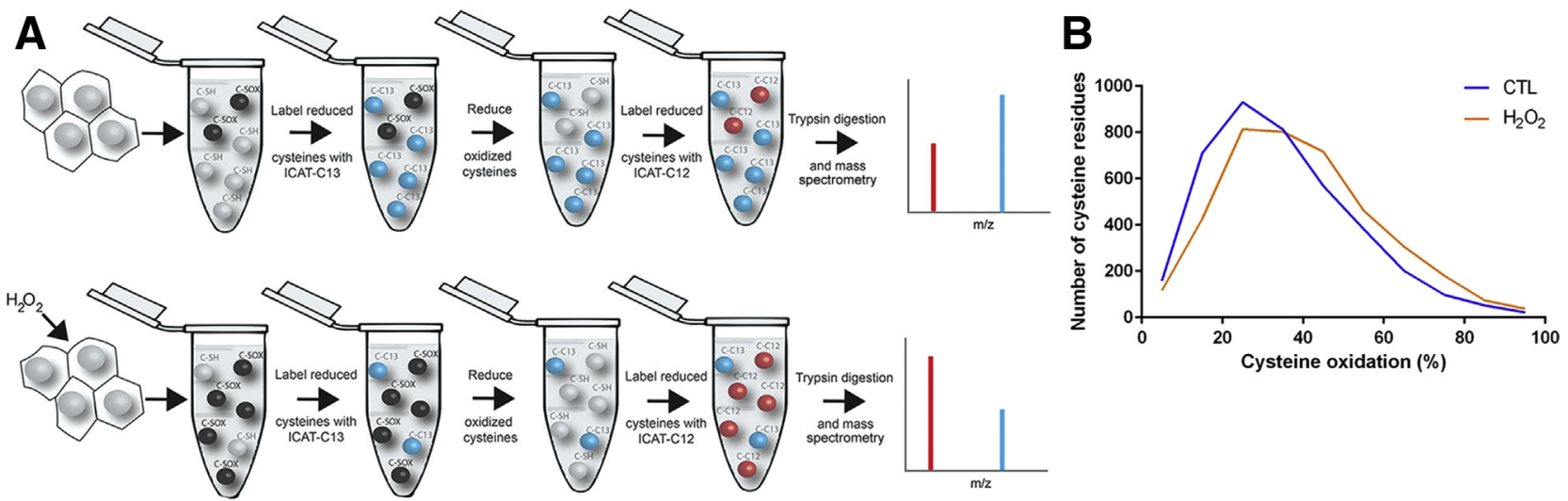

Figure 2 Identification of hydrogen peroxide $\left(\mathrm{H}_{2} \mathrm{O}_{2}\right)$-responsive signaling pathways in cultured epithelial cells. A: Graphical representation of isotope-coded affinity tag (ICAT) labeling method. B: Relative peptide oxidation levels significantly change in SK-CO-15 cells exposed to $1 \mathrm{mmol} / \mathrm{L} \mathrm{H}_{2} \mathrm{O}_{2}$ for 15 minutes. CTL, control. 
Table 1 Search Tool for the Retrieval of Interacting Genes/ Proteins Analysis to Detect the Functional Process Attributed to Peptides that Are Sensitive to Reactive 0xygen, as Detected by ICAT Analysis

\begin{tabular}{lcl}
\hline Pathway & No. of genes & $P$ value \\
\hline Ribosome & 10 & $1.06 \times 10^{-8}$ \\
Carbon metabolism & 8 & $3.3 \times 10^{-7}$ \\
Spliceosome & 7 & 0.00002 \\
Biosynthesis of amino acids & 5 & 0.00009 \\
Focal adhesions & 7 & 0.00034 \\
RNA transport & 6 & 0.00045 \\
MAPK signaling & 7 & 0.00124 \\
Tight junctions & 5 & 0.00141 \\
Regulation of cytoskeleton & 6 & 0.00233 \\
Cell cycle & 4 & 0.00787 \\
Adherens junctions & 3 & 0.0105 \\
\hline
\end{tabular}

ICAT, isotope-coded affinity tag; MAPK, mitogen-activated protein kinase.

diminished amounts of Cas, FAK, and Ras-related C3 botulinum toxin substrate 1 (Rac1) (Figure 3A) in the streptavidin agarose pull-down fraction, indicating that these proteins are oxidized by $1 \mathrm{mmol} / \mathrm{L} \mathrm{H}_{2} \mathrm{O}_{2}$; however, other cellular proteins, such as histone deacetylase 4 and $\mathrm{Abl}$ kinase, did not diminish for control versus hydrogen peroxide and, therefore, were not significantly oxidized by hydrogen peroxide. These data confirm that $\mathrm{H}_{2} \mathrm{O}_{2}$ applied exogenously to cultured human intestinal epithelium cells at $1 \mathrm{mmol} / \mathrm{L}$ is sufficient to elicit oxidation of cysteine residues within target proteins that control cell movement. Activation of Cas and FAK within focal adhesions occurs as a result of the phosphorylation of specific residues within these proteins. Because these phosphorylation events are critical to the activity of Cas and FAK within the focal adhesion complex, the extent to which these phosphorylation events and the cellular localization of these proteins were influenced by reactive oxygen was examined. The phosphorylation of FAK at residue Y397 (p-FAK Y397) is the primary upstream phosphorylation site controlling FAK activity. ${ }^{31}$ The p-FAK Y397 species is also known to localize and function within focal adhesions. ${ }^{32,33}$ Because of the established role of FAK in modulating the activity of Cas at focal adhesions, and reports of FAK altering endothelial barrier properties, ${ }^{17-22}$ its localization in the epithelium in response to reactive oxygen was examined. Antibodies against total FAK, p-FAK Y397, or p-FAK Y861 were used to identify the cellular localization of FAK and its phosphorylated species. Immunostaining analysis revealed that at steady state, total FAK and p-FAK Y861 localized to the cell junctions (Figure 3B), whereas p-FAK Y397 did not, and was primarily in the focal adhesions and cytosol (data not shown). Focal adhesion staining was positive for p-FAK Y861 (Figure 3C), suggesting that different forms of p-FAK Y861 might be shuttling between focal adhesions and cell junctions through a controlled phosphorylation-dependent mechanism, or, alternatively, total FAK is being controlled at these sites by kinase/phosphatase regulation of $\mathrm{Y} 861$. Exposure to $1 \mathrm{mmol} / \mathrm{L} \mathrm{H}_{2} \mathrm{O}_{2}$ for 15 minutes increased the levels of FAK Y861 in the junctions, demonstrating a redox-dependent component to FAK's localized activity in the junctions (Figure 3C). Immunoblot analysis of SK-CO-1 cultured cells subjected to $1 \mathrm{mmol} / \mathrm{L} \mathrm{H}_{2} \mathrm{O}_{2}$ for 15 minutes confirmed phosphorylation at Y861 and also detected phosphorylation of Cas at residue Y410, as previously reported, ${ }^{16}$ and at Y165, whereas Y249 was not detected to be phosphorylated in the same assay (Figure 3D). These data show that the phosphorylation state and subcellular localization of Cas and FAK are sensitive to altering hydrogen peroxide levels.

\section{FAK Localizes to Cell Junctions and Can Alter Barrier Activity}

FAK is also known to function in maintaining intestinal epithelia barrier integrity. ${ }^{34}$ The catalytic activity of FAK was disrupted using the inhibitor PF-562271, which binds in the ATP-binding cleft of FAK, thereby abrogating the kinase activity of FAK. Inhibition of FAK activity in SK-CO-1 cells resulted in a significant increase in transepithelial resistance, which was in contrast to a decrease in transepithelial resistance observed in these cells when incubated in the presence of 1 $\mathrm{mmol} / \mathrm{L} \mathrm{H}_{2} \mathrm{O}_{2}$ (Figure $4 \mathrm{~A}$ ). Inhibition of FAK activity with PF562271 also reduces the levels of FAK phosphorylation at Y397, as well as the phosphorylation of Cas at Y410 (Figure 4B), demonstrating a link between FAK catalytic activity and Cas phosphorylation. Evidence for this association was further demonstrated by showing the inhibition of FAK activity with PF-562271 disrupted the Cas/Crk complex, where Cas failed to coimmunoprecipitate with Crk after the inhibition with FAK (Figure 4C). As a control, these data were similar to the effect of activating ABL kinase using 5-[3-(4-fluorophenyl)1-phenyl-1H-pyrazol-4-yl]-2,4-imidazolidinedione, whose increased activity is known to disrupt the Cas/Crk complex (Figure 4C). Taken together, these observations indicate a signaling role for $\mathrm{FAK}$, and potentially Cas, in the cell junctions to regulate barrier properties during repair. To determine whether the effects of FAK inhibition on improved barrier function took place at the adherens junctions or tight junctions, the corresponding levels of $\beta$-catenin (adherens signaling) and myosin light chain (tight junction signaling) phosphorylation were measured in response to PF-562271 inhibition of FAK. A reduction in FAK phosphorylation at Y397 was detected after 5 minutes of incubation with PF-562271, and levels of myosin light chain S18/19 decreased slightly by 20 minutes and continued to decrease along the time course. A similar decrease in levels of $\beta$-catenin phosphorylation at S552, which leads to its disassociation from cell-cell contacts, was observed after incubation with PF-562271 (Figure 4D). These data suggest that hydrogen peroxide affects signaling at both the tight junctions and adherens junctions in an FAK-dependent manner. 
A

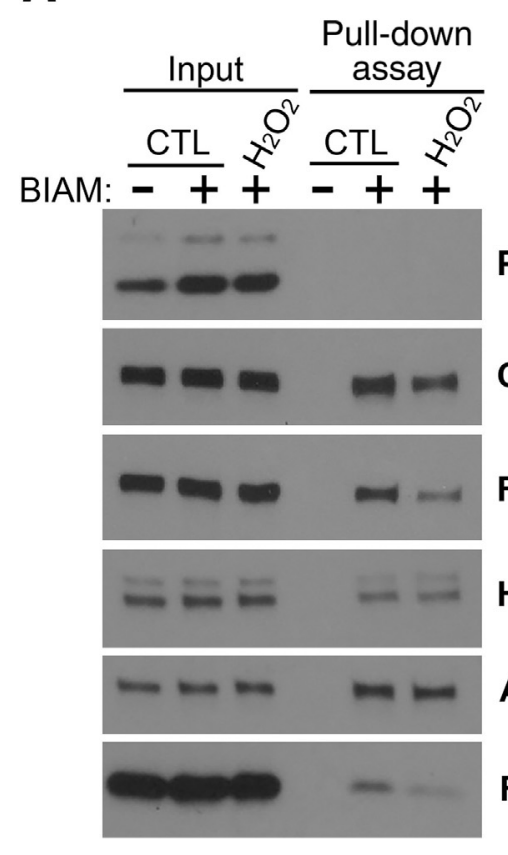

Prap-1

Cas

FAK

HDAC4

$A B L$

Rac1

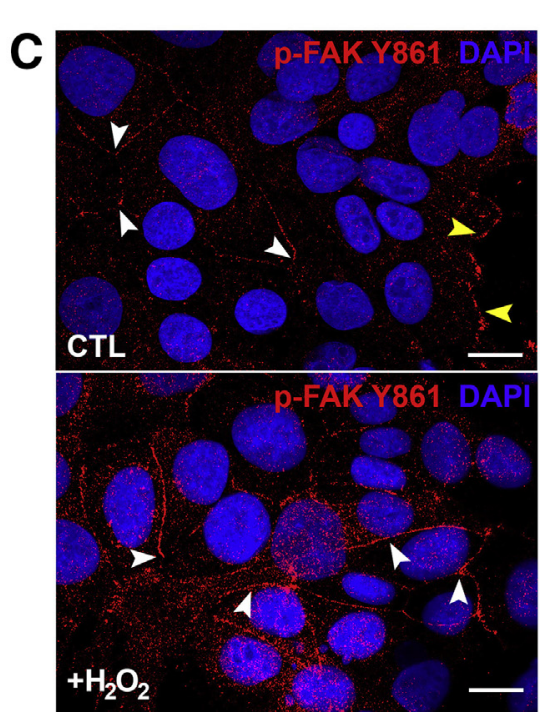

B
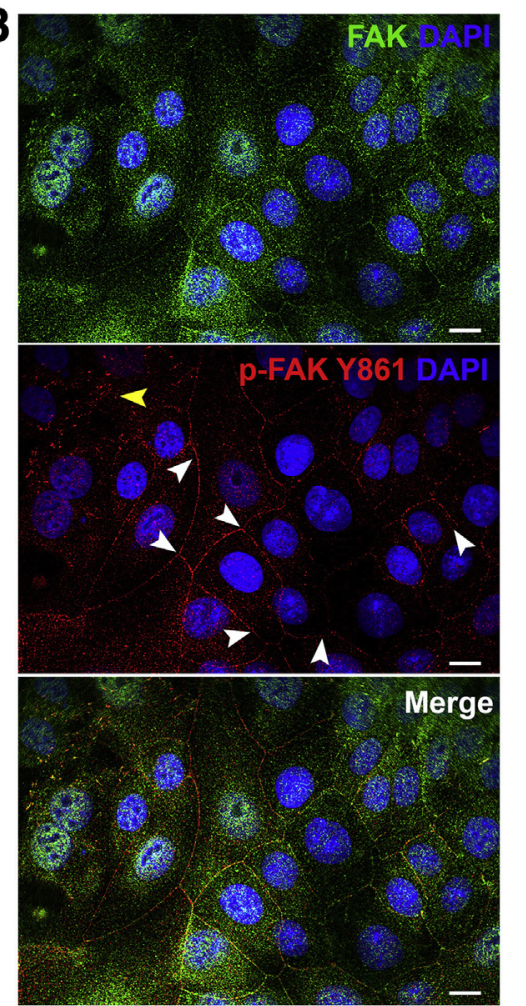

D

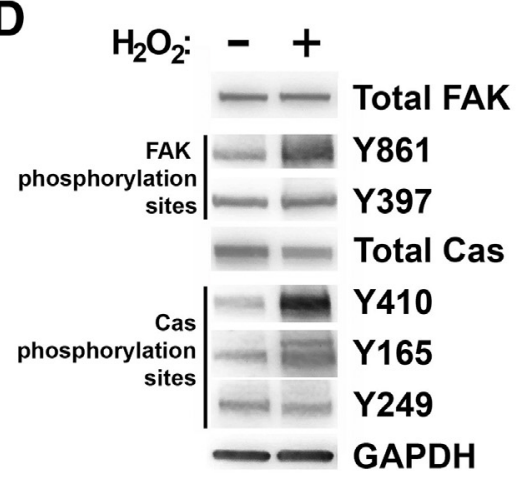

Figure 3 Hydrogen peroxide $\left(\mathrm{H}_{2} \mathrm{O}_{2}\right)$ specifically oxidizes Crk-associated substrate (Cas), focal adhesion kinase (FAK), and Ras-related C3 botulinum toxin substrate 1 (Rac1). A: Biotiniodoacetamide (BIAM) pull-down analysis of proteins extracted from SK-C0-15 cells after exposure to $1 \mathrm{mmol} / \mathrm{L}$ exogenous $\mathrm{H}_{2} \mathrm{O}_{2}$ for 15 minutes. Protein bands and relative intensity were detected by Western blot analysis using antibodies specific to proline-rich acidic protein 1 (Prap-1), histone deacetylase 4 (HDAC4), FAK, CAS, Abelson murine leukemia viral oncogene homolog (ABL), and Rac1. Blots shown are representative of at least three replicate experiments. B: Immunofluorescence analysis of SK-CO-15 cells for the detection of total FAK and phosphorylated FAK ( $p-F A K$ ) at residue Y861. Total FAK localized to the cytosol, focal adhesions, nucleus, and cellular junctions, whereas phosphorylated FAK Y861 primarily localizes to cell junctions, as indicated by the white arrowheads. Focal adhesions are indicated by the yellow arrowhead. C: Immunofluorescence analysis of SK-CO-15 cells exposed to $1 \mathrm{mmol} / \mathrm{L}$ exogenous $\mathrm{H}_{2} \mathrm{O}_{2}$ for the detection of phosphorylated FAK at residue Y861, which primarily localizes to cell junctions, as indicated by the white arrowheads. Focal adhesions are indicated by the yellow arrowheads. D: Immunoblot analysis for the detection of phosphorylated FAK at residue Y397 or Y861, and of phosphorylated Cas at residue Y410, Y165, or Y295, before and after exposure of SK-CO-15 to $1 \mathrm{mmol} / \mathrm{L} \mathrm{H}_{2} \mathrm{O}_{2}$. Scale bars $=20 \mu \mathrm{m}$ (B and C). CTL, control; GAPDH, glyceraldehyde-3phosphate dehydrogenase.

\section{FAK and $\mathrm{p}$-Cas Interact with Z0-1}

To test whether p-Cas or FAK physically interact with elements in the tight or adherens junctions and gain further insight into how the relocalization of these proteins might affect barrier function, proximity ligation assays were performed on SK-CO- 1 cells exposed to $1 \mathrm{mmol} / \mathrm{L} \mathrm{H}_{2} \mathrm{O}_{2}$ for 15 minutes. If two proteins are within approximately $40 \mathrm{~nm}$ of each other, possibly within actual physical contact, proximity ligation assay allows for complementary oligo-paired and conjugated secondary antibodies recognizing the primary antibodies of two different proteins in question to form a DNA heteroduplex that can be ligated and serves as a template to incorporate DNA polymerase-inserted fluorescent nucleotide that can be visualized and quantified by fluorescence microscopy. Although no coligation was detected in untreated cells, indicating no interaction, a strong coligation signal between the tight junction protein zonula occludens-1 (ZO-1) and p-Cas in a chicken-wire pattern, indicative of junctional staining, was detected 

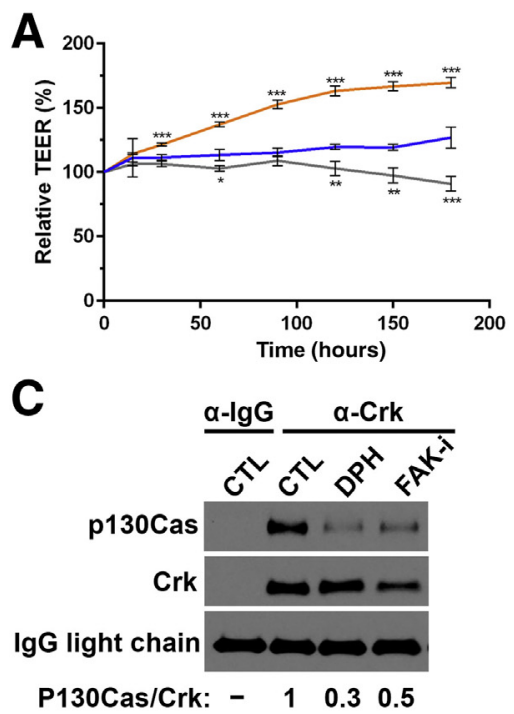

B

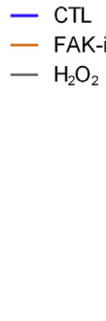

D

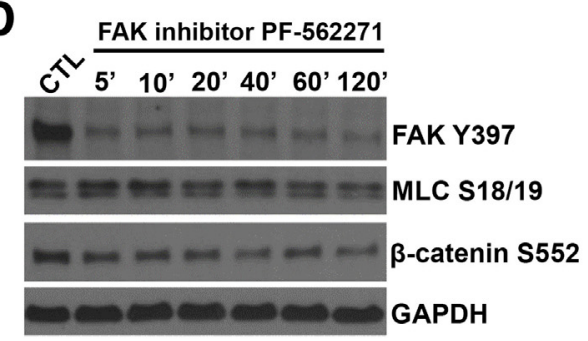

Figure 4 Focal adhesion kinase (FAK) localizes to cellular junctions and can alter barrier activity. A: Measurement of transepithelial electrical resistance (TEER) of cultured SK-CO-15 cells treated with FAK inhibitor (FAK-i) PF-562271 or with $1 \mathrm{mmol} / \mathrm{L}$ exogenous $\mathrm{H}_{2} \mathrm{O}_{2}$. One-way analysis of variance at each time point compares FAK-i and $\mathrm{H}_{2} \mathrm{O}_{2}$ treatment groups with control (CTL). B: Immunoblot analysis for the detection of phosphorylated FAK or Crk-associated substrate (Cas) at the indicated residues in cultured SKC0-15 cells treated with the FAK inhibitor PF562271. C: Coimmunoprecipitation and immunoblot analysis to detect interactions between Crk and Cas. D: Immunoblot analysis for the detection of the phosphorylation of proteins that are associated with tight junctions or adherens junctions for up to 2 hours in cultured SK-CO-15 cells treated with the FAK inhibitor PF-562271. ${ }^{*} P<0.05,{ }^{* *} P<0.01$, and ${ }^{* * *} P<0.001$. DPH， 5-[3-(4-fluorophenyl)-1-phenyl-1H-pyrazol-4yl]-2,4-imidazolidinedione; GAPDH, glyceraldehyde3-phosphate dehydrogenase; MLC, myosin light chain; RAN, GTP-binding nuclear protein Ran. after a 15-minute exposure to hydrogen peroxide (Figure 5A). In addition, ligation signal was detected between ZO-1 and FAK in both untreated SK-CO-1 cells and at 3.5-fold higher in SK-CO-1 cells exposed to hydrogen peroxide (Figure 5B). No signal was detected in control experiments, in which primary antibodies were omitted in the assay (Figure 5A). These data indicate a direct contact between $\mathrm{ZO}-1$ and Cas after hydrogen peroxide treatment and an increased interaction between FAK and ZO-1 after hydrogen peroxide treatment.
A
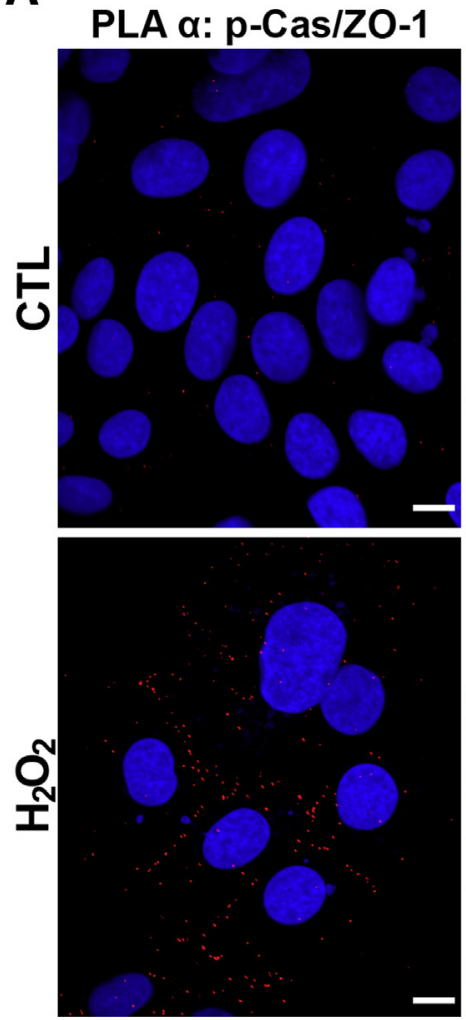

PLA $\alpha: F A K / Z O-1$
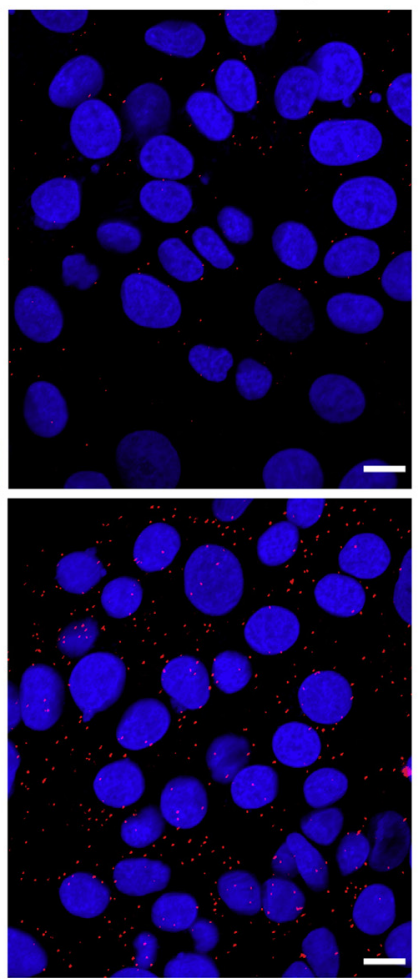

PLA a: No first-degree antibody

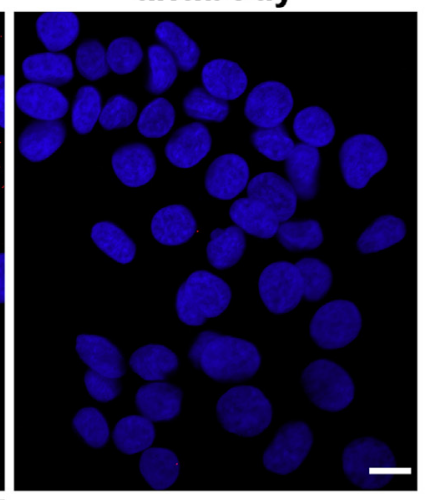

B Average proximity ligation events FAK and ZO-1

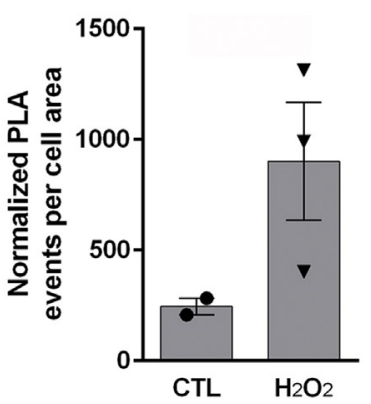

Figure 5 Focal adhesion kinase (FAK) and phosphorylated Crk-associated substrate ( $p$-Cas) interact with the zonula occludens-1 (Z0-1) tight junction protein. A: Immunofluorescence analysis of proximity ligation assay (PLA) to detect interactions between $p$-Cas and Z0-1 (indicated in red). PLA-negative controls (CTLs) were run in the absence of primary antibodies, but included secondary antibodies, ligation, and polymerase reaction. B: PLA analysis of FAK and ZO-1 before and after exogenous hydrogen peroxide $\left(\mathrm{H}_{2} \mathrm{O}_{2}\right)$ exposure. Groups were compared using a two-tailed $t$-test $(P=0.13)$. Scale bars $=20 \mu \mathrm{m}(\mathbf{A})$. 


\section{Active Rac1 Increases p-Cas Accumulation in Cell Junctions}

A regulator protein of Cas and FAK activity is the Rho family, small GTP-binding protein Rac1. Rac1-Cas-FAK signaling is connected to integrin signaling to regulate cellular stiffness and cell cycle through modifications in the cytoskeleton. ${ }^{35}$ These processes are also critical molecular events during wound healing in tissue. All three proteins, FAK, Cas, and Rac1, are oxidized by the addition of exogenous hydrogen peroxide (Figure 3), indicating that this pathway can be altered on increases in levels of reactive oxygen. To test the effect of active Rac1 on p-Cas localization, SK-CO-15 cells, transfected with a plasmid harboring an active form of Rac1 (G12V), were treated with $1 \mathrm{mmol} / \mathrm{L} \mathrm{H}_{2} \mathrm{O}_{2}$ for 15 minutes. In the absence of hydrogen peroxide, p-Cas is primarily located in the cytoplasm and focal adhesions. However, after exposure to hydrogen peroxide, $\mathrm{p}$-Cas rapidly increases its presence in the cell junctions (Figure 6). Constitutive expression of Rac1 $(\mathrm{G} 12 \mathrm{~V})$ caused an increase in the cytoplasmic accumulation of $\mathrm{p}$-Cas that primarily turned to defined junctional staining (similar to junctional adhesion molecule A localization) on addition of hydrogen peroxide (Figure 6). Although p-Cas clearly accumulates in and around the junctional domains after oxidation, the presence of active Rac1 during hydrogen peroxide exposure produces a much more pronounced accumulation of p-Cas in the junctions, indicative of enhanced targeting. Thus, active Rac1 (G12V) enhances p-Cas accumulation in cell junctions in response to elevated levels of reactive oxygen.

\section{Isotope-Coded Affinity Tags Identify Pak2 as a Mediator of Oxidative Signaling}

Another protein that was identified to be significantly oxidized in response to hydrogen peroxide exposure using ICAT analysis was Pak2, which was significantly oxidized $(P<0.05)$ at $\mathrm{C} 352$ (Figure 2 and Supplemental Table S1). More important, Pak1 is known to function in the regulation of Rac $1,{ }^{36}$ which itself is sensitive to oxidation in response to hydrogen peroxide exposure (Figure 3). Analysis of the Pak2 amino acid sequences reveals that $\mathrm{C} 352$ lies within a C-terminal domain (amino acids 330 to 490) containing five cysteines that likely play an intrinsic structural role through disulfide bond formation. Using the BIAM cysteine labeling pull-down assay on SK-CO-15 cell lysates prepared from hydrogen peroxide-treated or untreated cultures, an increase in the levels of Pak2 oxidation was observed, confirming identification of Pak 2 as a reactive oxygen-sensitive protein (Figure 7A). As a functional corollary, it was tested if inhibiting Pak2 activity before exposure of cells to hydrogen peroxide would block the accumulation of p-Cas in cell junctions. Pretreating SK-CO-15 cells with FRAX597, a small-molecule inhibitor of the p21-activated kinase 2, for 1 hour disrupted the ability of p-Cas to accumulate in the junctions after hydrogen peroxide exposure (Figure 7B). FAK, however, still remained in the junctions after inhibition of Pak2. These data suggest that Pak2 contributes to the regulatory events that induce the accumulation of p-Cas in cell junctions in response to increases in levels of reactive oxygen, thereby implicating Pak2 as another protein that is responsive to elevated reactive oxygen levels, including reactive oxygen generated by leukocytes within wounds during restitution.

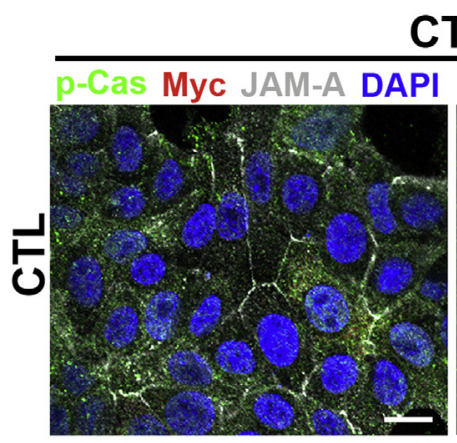

CTL
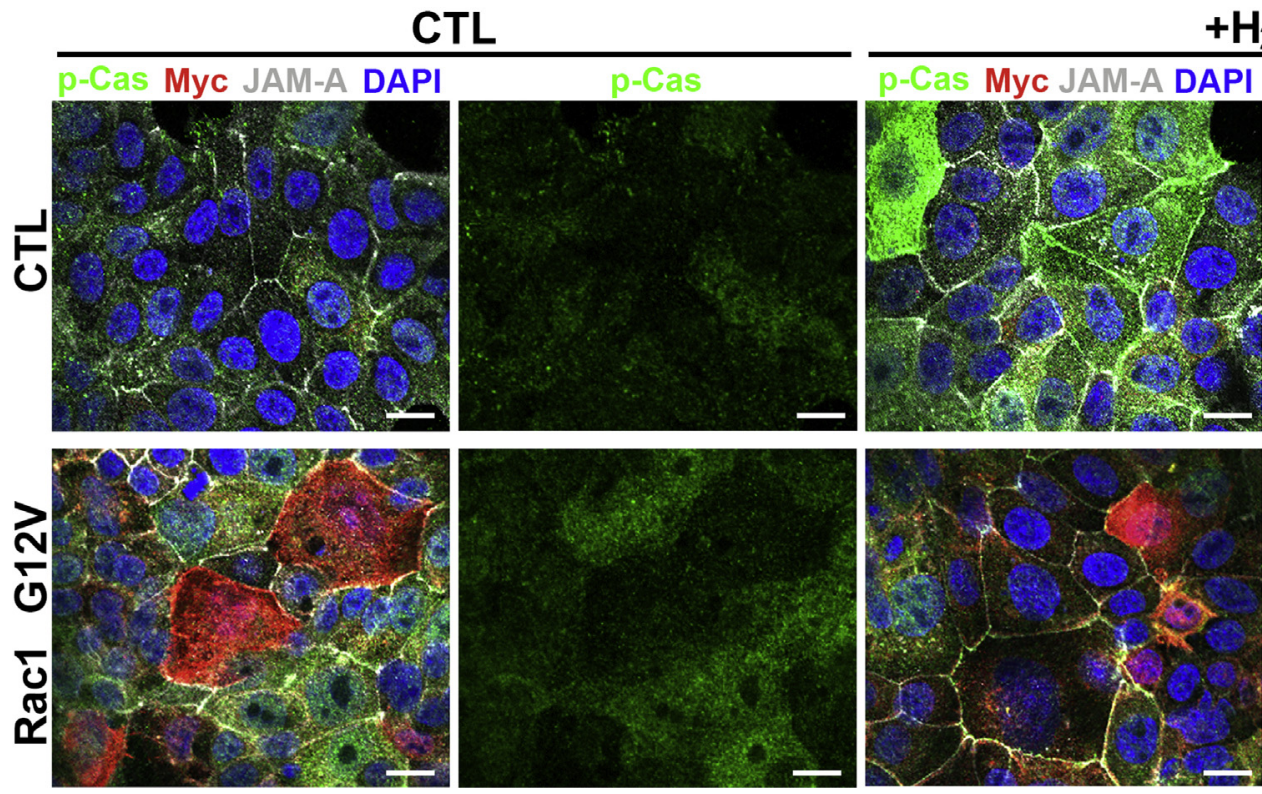

$+\mathrm{H}_{2} \mathrm{O}_{2}$
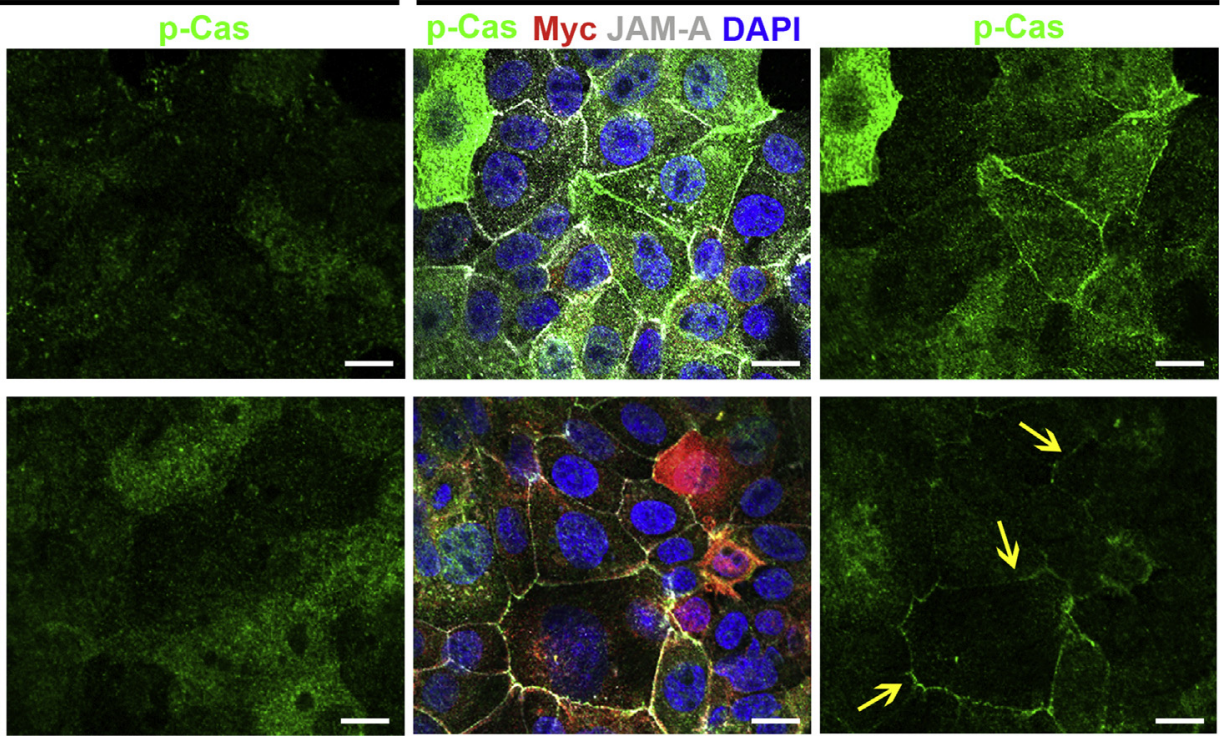

Figure 6 Active Ras-related C3 botulinum toxin substrate 1 (Rac1) increases phosphorylated Crk-associated substrate ( $\mathrm{p}$-Cas) accumulation at cellular junctions. Immunofluorescence analysis of p-Cas (green) and junctional adhesion molecule A (JAM-A; gray) localization in SK-C0-15 cells at 48 hours after transfection with a plasmid harboring a myc-tagged G12V Rac1 open reading frame (red) or empty vector control (CTL) after exposure of cells to $1 \mathrm{mmol} / \mathrm{L} \mathrm{H}_{2} \mathrm{O}_{2}$ for 15 minutes. Yellow arrows indicate the more localized appearance of $p$-Cas labeling in cell-cell junctions. DNA is stained with DAPI (blue). Scale bars $=20 \mu \mathrm{m}$. 
A

BIAM pull-down assay

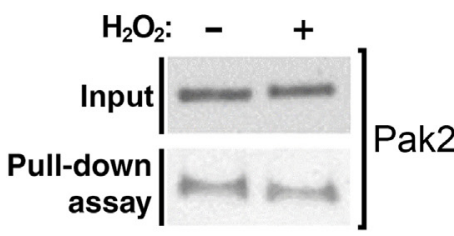

Ratio: $0.8 \quad 0.6$

(Pull-down assay/

Input)
B
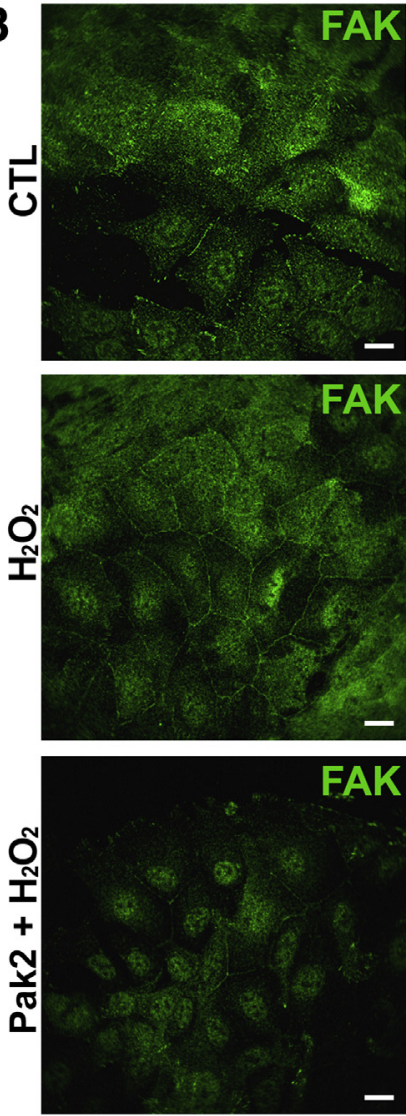
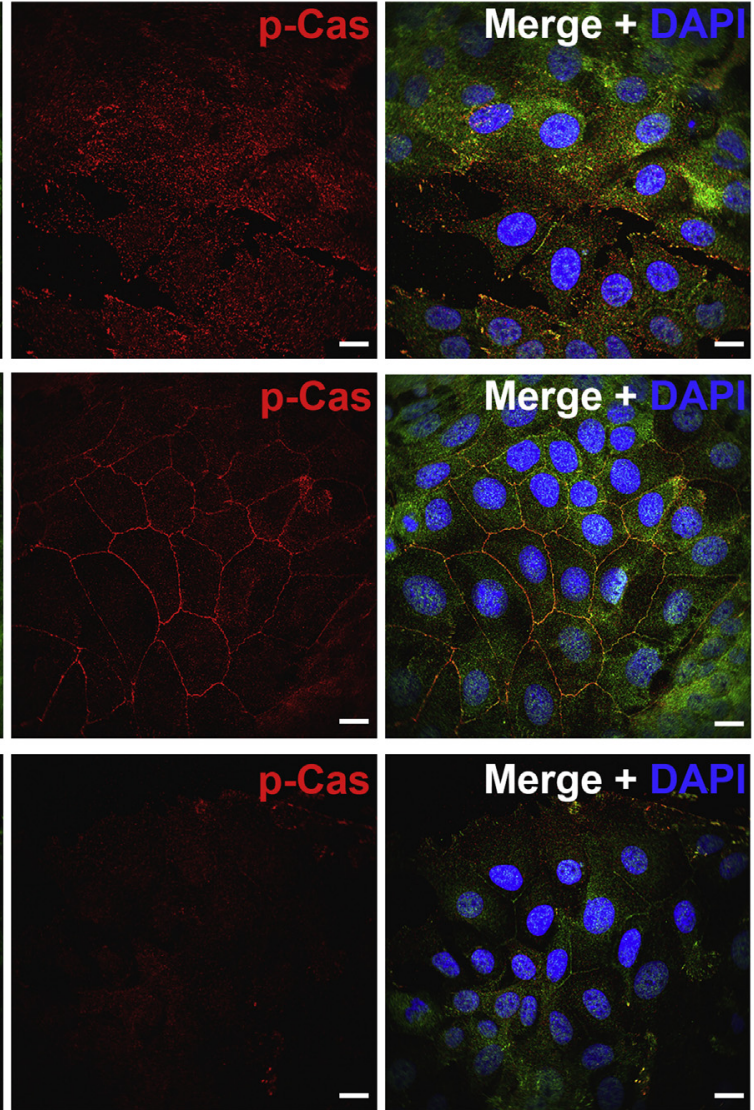

Figure 7 Isotope-coded affinity tags identify p21-activated kinase 2 (Pak2) as a mediator of oxidative signaling. A: Biotin-iodoacetamide (BIAM) labeling analysis of Pak2 from SK-CO-15 cells treated with $1 \mathrm{mmol} / \mathrm{L} \mathrm{H}_{2} \mathrm{O}_{2}$ for 15 minutes. Immunoblot analysis was used to detect the levels of total Pak2. Immunoblot shown is representative of at least three replicate experiments. B: Immunofluorescence analysis of SK-C0-15 cells treated with the Pak2 inhibitor FRAX597 at 2 $\mu \mathrm{mol} / \mathrm{L}$ for 1 hour, followed by exposure to $1 \mathrm{mmol} / \mathrm{L} \mathrm{H}_{2} \mathrm{O}_{2}$ for 15 minutes. Analysis detected phosphorylated Crk-associated substrate ( $\mathrm{p}$-Cas; red), and total focal adhesion kinase (FAK; green) localization in nuclei was stained with DAPI (blue). Scale bars $=20 \mu \mathrm{m}$ (B). CTL, control.

\section{Discussion}

The data presented in this article demonstrate that proteins that form focal adhesions in the epithelium, including Cas and FAK, are phosphorylated within intestinal wounds in conditions of elevated reactive oxygen. In vivo reactive oxygen species can be generated by the catalytic complex that includes gp91phox, which is known to be expressed within infiltrating immune cells, such as neutrophils at the site of injury. This study shows that Cas and FAK are not phosphorylated within wounds of mice that are null in gp91phox or in mice depleted of neutrophils using an antiLy6G antibody. To model synchronous exposure of the epithelium to higher levels of immune cell-generated reactive oxygen, cultured epithelial cells were exposed to exogenous hydrogen peroxide, which resulted in the oxidation of thiol groups of specific cysteine residues within Cas, FAK, and Racl. The phosphorylation state and the subcellular localization of Cas and FAK are sensitive to altering reactive oxygen levels. Finally, using ICAT-based proteomics, PAK2, which is an effector protein that links Rho GTPases to cytoskeletal reorganization, was identified as another protein that acts as a sensor to elevated levels of reactive oxygen. Taken together, these analyses indicate that oxidation of epithelial cell proteins by exogenously produced reactive oxygen within an intestinal wound orchestrates a network of signaling events that modulate restitution and tissue repair. Furthermore, these results imply that inflammatory neutrophil products, previously understood as deleterious to tissues, may have direct effects in initiating events in the wound healing process.

The sensitivity of focal adhesion proteins to reactive oxygen has previously been shown to modulate cell migration. ${ }^{37}$ However, the influence of reactive oxygen in the cross talk between focal adhesions and cell junctions remained unclear. Cas has long been known to target multiple cellular processes, and Rac1 is a primary mediator of Cas signaling. ${ }^{38,39}$ The Cas binding partner Crk was recently reported to facilitate Cas signaling by modulating the Rac1/c-Jun N-terminal kinase (JNK) pathway after integrin-mediated activation. ${ }^{16}$ Our studies show that Cas also plays a further role in intermediate signaling events that function in the lateral to basolateral shift in Cas localization within a tissue wound microenvironment after exposure to 
immune cell-generated reactive oxygen. Interestingly, Cas has been shown to regulate JNK signaling in a hydrogen peroxide-dependent manner, ${ }^{40}$ a mechanism that has been suggested to involve the activity of Rac1, which is another redox-sensitive protein. Furthermore, prolonged JNK signaling is widely recognized as proapoptotic. These observations suggest that elevated levels of exogenous reactive oxygen at the villus tips surrounding inflicted wounds may also stimulate apoptosis and/or anoikis to accommodate the increase in cell proliferation within stem cell compartments and the movement of the adjacent enterocytes along the crypt axis during wound repair. ${ }^{41}$ The role of Cas in regulating anoikis has also been reported in three different studies, ${ }^{42-44}$ in which Cas dephosphorylation and Cas cleavage were shown to be required to induce signaling events involved in anoikis, ${ }^{42,44}$ via a mechanism regulated by the chemokine CXCL12. ${ }^{43}$ These multiple roles of Cas highlight the complex and coordinated progression of cellular events that occur within a wound bed during the healing process.

The localization of p-Cas to cell junctions after injury may play a role in regulating barrier integrity during healing. Specifically, FAK has also been shown to function in regulating barrier activity in the endothelium ${ }^{22}$ and epithelium, ${ }^{34,45}$ and its accumulation at cell junctions under baseline conditions suggests it plays a direct role regulating epithelial barrier integrity in healthy gut tissue. The redox-driven changes in p-Cas localization were further dissected at cell junctions after exposure to reactive oxygen by showing that both Cas and FAK interact with proteins that form adherens or tight junctions, thereby indicating functions for these proteins in maintaining epithelial barrier integrity. A significant increase in the association of p-Cas with ZO-1 after hydrogen peroxide exposure was detected, whereas FAK associated with ZO-1 before and after hydrogen peroxide exposure. The observation of a direct association between FAK and ZO- 1 is consistent with the results of other studies. ${ }^{23}$ Because similar increases between E-cadherin and FAK, or between E-cadherin and p-Cas, were not observed, it can be concluded that reactive oxygen-induced changes observed in p-Cas and FAK at cell junctions likely occur through signaling events at tight junctions. In addition, these data generated using proximity ligation corroborate the immunofluorescence analysis data showing that $\mathrm{p}$-Cas localizes to cell junctions only after oxidation, whereas FAK localizes to cell junctions before and after oxidation. Taken together, the increase in FAK/ZO-1 binding, and the accumulation of phosphorylated FAK at Y861 at cell junctions after exposure to hydrogen peroxide, coupled with the increase in epithelial barrier integrity after the pharmacologic blocking of FAK activity, suggests that reversible phosphorylation of FAK at Y861 is redox sensitive and regulates its binding to $\mathrm{ZO}-1$ at tight junctions. These events likely influence intestinal barrier properties during injury repair, especially after exposure to elevated reactive oxygen levels as a result of the recruitment of leukocytes to wound beds.
Finally, ICAT proteomics was used to identify additional candidate proteins and corresponding cysteine residues that are sensitive to reactive oxygen. A current limitation of the ICAT mass spectrometry analysis is the inability to capture all peptides during a run, and, as such, peptides from Cas or FAK could not be directly detected in the proteomic analysis. However, many other proteins involved in pathways intersecting the focal adhesions, cell junctions, and cytoskeleton pathways, which are known to be regulated by Cas and FAK, including Abl kinase, were detected. Blocking Abl kinase activity with imatinib mesylate (Gleevec, Novartis International AG, Cambridge, MA) reduces the accumulation of p-Cas at cell junctions after exposure to hydrogen peroxide. ${ }^{16}$ In the current study, Pak2 was identified as playing a role in the reactive oxygen-mediated accumulation of p-Cas at cell junctions. Pak proteins, or p21-associated kinases, are regulators of GTPase activity and, in particular, of Rac1 activity. Given the enhanced accumulation of $\mathrm{p}$-Cas at cell junctions during constitutive expression of active Rac1, or during exposure to exogenous hydrogen peroxide, redox-dependent mechanisms that may be regulated by infiltrating leukocytes at the site of intestinal injury were described further. This study shows that infiltrating leukocytes generate high levels of extracellular reactive oxygen that function in orchestrating focal adhesion-to-cell junction interaction in the adjacent epithelium, where numerous scaffolding molecules, such as Cas, FAK, Abl, and Pak2, as well and signaling modules within adherens and tight junctions augment intestinal barrier strength during tissue wound repair.

\section{Acknowledgment}

We thank Charles Parkos (University of Michigan, Ann Arbor, MI) for providing the SK-CO-15 cells.

\section{Supplemental Data}

Supplemental material for this article can be found at http://doi.org/10.1016/j.ajpath.2019.07.017.

\section{References}

1. Peterson LW, Artis D: Intestinal epithelial cells: regulators of barrier function and immune homeostasis. Nat Rev Immunol 2014, 14:141-153

2. Barker N: Adult intestinal stem cells: critical drivers of epithelial homeostasis and regeneration. Nat Rev Mol Cell Biol 2014, 15:19-33

3. Alam A, Leoni G, Wentworth CC, Kwal JM, Wu H, Ardita CS, Swanson PA, Lambeth JD, Jones RM, Nusrat A, Neish AS: Redox signaling regulates commensal-mediated mucosal homeostasis and restitution and requires formyl peptide receptor 1. Mucosal Immunol 2014, 7:645-655

4. Campbell EL, Colgan SP: Control and dysregulation of redox signalling in the gastrointestinal tract. Nat Rev Gastroenterol Hepatol 2019, 16:106-120

5. Jones RM, Neish AS: Redox signaling mediated by the gut microbiota. Free Radic Biol Med 2017, 105:41-47 
6. Leoni G, Neumann PA, Kamaly N, Quiros M, Nishio H, Jones HR, Sumagin R, Hilgarth RS, Alam A, Fredman G, Argyris I, Rijcken E, Kusters D, Reutelingsperger C, Perretti M, Parkos CA, Farokhzad OC, Neish AS, Nusrat A: Annexin A1-containing extracellular vesicles and polymeric nanoparticles promote epithelial wound repair. J Clin Invest 2015, 125:1215-1227

7. Uhlinger DJ, Tyagi SR, Inge KL, Lambeth JD: The respiratory burst oxidase of human neutrophils: guanine nucleotides and arachidonate regulate the assembly of a multicomponent complex in a semirecombinant cell-free system. J Biol Chem 1993, 268:8624-8631

8. Lambeth JD, Neish AS: Nox enzymes and new thinking on reactive oxygen: a double-edged sword revisited. Annu Rev Pathol 2014, 9:119-145

9. Babior BM: Oxygen-dependent microbial killing by phagocytes: 1. N Engl J Med 1978, 298:659-668

10. Hall CHT, Campbell EL, Colgan SP: Neutrophils as components of mucosal homeostasis. Cell Mol Gastroenterol Hepatol 2017, 4:329-337

11. Alam A, Leoni G, Quiros M, Wu H, Desai C, Nishio H, Jones RM, Nusrat A, Neish AS: The microenvironment of injured murine gut elicits a local pro-restitutive microbiota. Nat Microbiol 2016, 1:15021

12. Rhee SG, Kang SW, Jeong W, Chang TS, Yang KS, Woo HA: Intracellular messenger function of hydrogen peroxide and its regulation by peroxiredoxins. Curr Opin Cell Biol 2005, 17:183-189

13. Barford D: The role of cysteine residues as redox-sensitive regulatory switches. Curr Opin Struct Biol 2004, 14:679-686

14. Terada LS: Specificity in reactive oxidant signaling: think globally, act locally. J Cell Biol 2006, 174:615-623

15. Ushio-Fukai M: Compartmentalization of redox signaling through NADPH oxidase-derived ROS. Antioxid Redox Signal 2009, 11:1289-1299

16. Matthews JD, Sumagin R, Hinrichs B, Nusrat A, Parkos CA, Neish AS: Redox control of Cas phosphorylation requires Abl kinase in regulation of intestinal epithelial cell spreading and migration. Am J Physiol Gastrointest Liver Physiol 2016, 311:G458-G465

17. Arnold KM, Goeckeler ZM, Wysolmerski RB: Loss of focal adhesion kinase enhances endothelial barrier function and increases focal adhesions. Microcirculation 2013, 20:637-649

18. Quadri SK: Cross talk between focal adhesion kinase and cadherins: role in regulating endothelial barrier function. Microvasc Res 2012, 83:3-11

19. Mehta D, Tiruppathi C, Sandoval R, Minshall RD, Holinstat M, Malik AB: Modulatory role of focal adhesion kinase in regulating human pulmonary arterial endothelial barrier function. J Physiol 2002, 539:779-789

20. Yuan SY, Shen Q, Rigor RR, Wu MH: Neutrophil transmigration, focal adhesion kinase and endothelial barrier function. Microvasc Res 2012, 83:82-88

21. Lee J, Borboa AK, Chun HB, Baird A, Eliceiri BP: Conditional deletion of the focal adhesion kinase FAK alters remodeling of the blood-brain barrier in glioma. Cancer Res 2010, 70:10131-10140

22. Schmidt TT, Tauseef M, Yue L, Bonini MG, Gothert J, Shen TL, Guan JL, Predescu S, Sadikot R, Mehta D: Conditional deletion of FAK in mice endothelium disrupts lung vascular barrier function due to destabilization of RhoA and Rac1 activities. Am J Physiol Lung Cell Mol Physiol 2013, 305:L291-L300

23. Cheng CY, Mruk DD: Regulation of blood-testis barrier dynamics by focal adhesion kinase (FAK): an unexpected turn of events. Cell Cycle 2009, 8:3493-3499

24. Ilic D, Mao-Qiang M, Crumrine D, Dolganov G, Larocque N, Xu P, Demerjian M, Brown BE, Lim ST, Ossovskaya V, Schlaepfer DD, Fisher SJ, Feingold KR, Elias PM, Mauro TM: Focal adhesion kinase controls pH-dependent epidermal barrier homeostasis by regulating actin-directed $\mathrm{Na}+/ \mathrm{H}+$ exchanger 1 plasma membrane localization. Am J Pathol 2007, 170:2055-2067

25. Usatyuk PV, Parinandi NL, Natarajan V: Redox regulation of 4hydroxy-2-nonenal-mediated endothelial barrier dysfunction by focal adhesion, adherens, and tight junction proteins. J Biol Chem 2006, 281:35554-35566

26. Dupre-Crochet S, Erard M, Nuss O: ROS production in phagocytes: why, when, and where? J Leukoc Biol 2013, 94:657-670
27. Matthews JD, Reedy AR, Wu H, Hinrichs BH, Darby TM, Addis C, Robinson BS, Go YM, Jones DP, Jones RM, Neish AS: Proteomic analysis of microbial induced redox-dependent intestinal signaling. Redox Biol 2019, 20:526-532

28. Campbell EL, Bruyninckx WJ, Kelly CJ, Glover LE, McNamee EN, Bowers BE, Bayless AJ, Scully M, Saeedi BJ, Golden-Mason L, Ehrentraut SF, Curtis VF, Burgess A, Garvey JF, Sorensen A, Nemenoff R, Jedlicka P, Taylor CT, Kominsky DJ, Colgan SP: Transmigrating neutrophils shape the mucosal microenvironment through localized oxygen depletion to influence resolution of inflammation. Immunity 2014, 40:66-77

29. Go YM, Roede JR, Orr M, Liang Y, Jones DP: Integrated redox proteomics and metabolomics of mitochondria to identify mechanisms of Cd toxicity. Toxicol Sci 2014, 139:59-73

30. Franceschini A, Szklarczyk D, Frankild S, Kuhn M, Simonovic M, Roth A, Lin J, Minguez P, Bork P, von Mering C, Jensen LJ: STRING v9.1: protein-protein interaction networks, with increased coverage and integration. Nucleic Acids Res 2013, 41:D808-D815

31. Hamadi A, Bouali M, Dontenwill M, Stoeckel H, Takeda K, Ronde P: Regulation of focal adhesion dynamics and disassembly by phosphorylation of FAK at tyrosine 397. J Cell Sci 2005, 118:4415-4425

32. Golubovskaya VM, Figel S, Ho BT, Johnson CP, Yemma M, Huang G, Zheng M, Nyberg C, Magis A, Ostrov DA, Gelman IH, Cance WG: A small molecule focal adhesion kinase (FAK) inhibitor, targeting Y397 site: 1-(2-hydroxyethyl)-3, 5, 7-triaza-1-azoniatricyclo [3.3.1.1(3,7)]decane; bromide effectively inhibits FAK autophosphorylation activity and decreases cancer cell viability, clonogenicity and tumor growth in vivo. Carcinogenesis 2012, 33:1004-1013

33. Schlaepfer DD, Hauck CR, Sieg DJ: Signaling through focal adhesion kinase. Prog Biophys Mol Biol 1999, 71:435-478

34. Ma Y, Semba S, Khan RI, Bochimoto H, Watanabe T, Fujiya M, Kohgo Y, Liu Y, Taniguchi T: Focal adhesion kinase regulates intestinal epithelial barrier function via redistribution of tight junction. Biochim Biophys Acta 2013, 1832:151-159

35. Bae YH, Mui KL, Hsu BY, Liu SL, Cretu A, Razinia Z, Xu T, Pure E, Assoian RK: A FAK-Cas-Rac-lamellipodin signaling module transduces extracellular matrix stiffness into mechanosensitive cell cycling. Sci Signal 2014, 7:ra57

36. Renkema GH, Pulkkinen K, Saksela K: Cdc42/Rac1-mediated activation primes PAK2 for superactivation by tyrosine phosphorylation. Mol Cell Biol 2002, 22:6719-6725

37. Basuroy S, Dunagan M, Sheth P, Seth A, Rao RK: Hydrogen peroxide activates focal adhesion kinase and c-Src by a phosphatidylinositol 3 kinase-dependent mechanism and promotes cell migration in Caco-2 cell monolayers. Am J Physiol Gastrointest Liver Physiol 2010, 299:G186-G195

38. Liu G, Li W, Gao X, Li X, Jurgensen C, Park HT, Shin NY, Yu J, He ML, Hanks SK, Wu JY, Guan KL, Rao Y: p130CAS is required for netrin signaling and commissural axon guidance. J Neurosci 2007, 27:957-968

39. Kiyokawa E, Hashimoto Y, Kobayashi S, Sugimura H, Kurata T, Matsuda M: Activation of Rac1 by a Crk SH3-binding protein, DOCK180. Genes Dev 1998, 12:3331-3336

40. Yoshizumi M, Abe J, Haendeler J, Huang Q, Berk BC: Src and Cas mediate JNK activation but not ERK1/2 and p38 kinases by reactive oxygen species. J Biol Chem 2000, 275:11706-11712

41. Shanmugathasan M, Jothy S: Apoptosis, anoikis and their relevance to the pathobiology of colon cancer. Pathol Int 2000, 50:273-279

42. Wei L, Yang Y, Zhang X, Yu Q: Cleavage of p130Cas in anoikis. J Cell Biochem 2004, 91:325-335

43. Wendt MK, Drury LJ, Vongsa RA, Dwinell MB: Constitutive CXCL12 expression induces anoikis in colorectal carcinoma cells. Gastroenterology 2008, 135:508-517

44. Wei L, Yang Y, Zhang X, Yu Q: Anchorage-independent phosphorylation of p130(Cas) protects lung adenocarcinoma cells from anoikis. J Cell Biochem 2002, 87:439-449

45. Playford MP, Vadali K, Cai X, Burridge K, Schaller MD: Focal adhesion kinase regulates cell-cell contact formation in epithelial cells via modulation of Rho. Exp Cell Res 2008, 314:3187-3197 